Article

\title{
Youth Empowerment Through Arts Education: A Case Study of a Non-Formal Education Arts Centre in Barcelona
}

\author{
Mariona Ferrer-Fons ${ }^{1, *}$, Marta Rovira-Martínez ${ }^{1}$, and Roger Soler-i-Martí ${ }^{2}$ \\ ${ }^{1}$ Department of Political and Social Sciences, Universitat Pompeu Fabra, Spain \\ 2 Department of Communication, Universitat Pompeu Fabra, Spain \\ * Corresponding author (mariona.ferrer@upf.edu)
}

Submitted: 30 September 2021 | Accepted: 7 January 2022 | Published: 20 April 2022

\begin{abstract}
This article discusses how non-formal arts education attenuates socioeconomic and cultural barriers in a vulnerable context. Although cultural capital has usually been conceived as dependent on high socioeconomic status, we explore the inclusiveness of a project of non-formal education and how it enhances the capacity of youth to achieve empowerment and self-confidence through the arts. We analyse the case study of a non-formal arts educational organisation located in a deprived neighbourhood of Barcelona (Spain) and identify several key factors associated with successful social inclusion and its limitations. We find that the pedagogical processes involved create both learning opportunities and social and interpersonal skills useful for the present and future lives of the young participants. Methodologically, the case study combines non-participant observation of the different activities of the organisation and semi-structured qualitative interviews with young people and educators. The article concludes with some recommendations for considering artistic non-formal education as a tool in any social inclusion agenda.
\end{abstract}

\section{Keywords}

artistic education; arts; empowerment; non-formal education; social inclusion; vulnerable youth

\section{Issue}

This article is part of the issue "Promoting Social Inclusive Experiences in Uncertain Times" edited by Ana Belén Cano-Hila (University of Barcelona).

(C) 2022 by the author(s); licensee Cogitatio (Lisbon, Portugal). This article is licensed under a Creative Commons Attribution 4.0 International License (CC BY).

\section{Introduction}

The Universal Declaration of Human Rights of 1948 (art. 27) states that everyone has the right to freely participate in the cultural life of the community, to enjoy the arts, and to share in scientific advancement and its benefits. This statement already highlights that cultural participation and equal access to culture entails benefits and well-being for individuals. Despite there being different forms of cultural participation such as creating, volunteering, or simply being a spectator in many offline and online cultural activities (Council of Europe, 2017; UNESCO, 2012), it seems to be that formal culture, or "legitimate culture," including artistic expression, is less accessible to the working class and vulnerable population (Eurostat, 2019), taking into account the cul- tural distance and the influence of habitus explained by Bourdieu's theory (Bourdieu \& Passeron, 1990; Willekens \& Lievens, 2014). This means that cultural capital is a cause of inequality among young people, as a consequence of the reproduction of social inequalities. From the theory of Bourdieu (1984), those in advantaged socioeconomic positions have greater familiarity with high-status cultural practices (such as playing musical instruments, painting, or acting). In the face of this, we propose another point of view, one based on the power of arts and culture to empower young people in vulnerable situations. The question that we discuss here is how cultural participation employing an inclusive strategy through non-formal education can subvert this role of reproduction and turn it into an opportunity for empowering young people in a vulnerable context. 
To explore this, we focus on how non-formal music and arts education can have a great emancipatory capacity and a higher profile in the social inclusion agenda through its potential for personal and community empowerment (Forrest-Bank et al., 2016; Pineda-Herrero et al., 2018). We argue, first, that the particular appeal of arts to expressivity and emotions represents an extraordinary way to encourage personal growth, collective recognition, and self-esteem, and contribute to the empowerment of young people in a vulnerable environment. Secondly, we contend that non-formal education allows for the relaxation of the procedures and standardisation of formal education, offering the opportunity to include dialogical and horizontal educational dynamics that break down some of the barriers that young people from low-income households face in other educational contexts. Thus, despite the role of cultural participation in the reproduction of social inequalities, in certain circumstances and contexts, non-formal arts education can become a transformative tool to promote the empowerment of young people in situations of social vulnerability.

This is presented through a case study of a nonformal arts education entity located in the Raval neighbourhood in Barcelona (Spain) that works with children and young people, many of whom are at risk of social exclusion. The educational proposal of this social actor is based on teaching them to sing, play an instrument, musical sensitivity, dance or act, offering them specific courses and combining different art expressions with special projects involving all the pupils of the school into the community. Thus, the aim of this arts centre is not only to teach art in all its forms, but to create a broader and inclusive educational and community process through non-formal artistic educational practices that build the youths' self-esteem, the feeling of belonging to a community, values of cooperation, empathy, and critical thinking.

The case is relevant as an example of how non-formal arts education can be an appropriate formula to provide an environment for empowerment in a vulnerable neighbourhood. As presented here, regardless of the personal and collective empowering ability of the project, there is constant tension with structural constraints and individual circumstances that limit the impact on reversing social inequalities. This article explores how the arts centre works and how, despite all the obstacles, it has become a model of effective youth social inclusion. The features of an environment conducive to genuine social inclusion and empowerment processes (Berg et al., 2009; Cargo et al., 2003) and the values which are central to this are also considered.

\section{Theoretical Framework}

Inequalities in cultural participation of the youth population reflect inequalities in the socioeconomic sphere at large. Since Bourdieu's original conceptualisation of the concept of cultural capital (Bourdieu, 1977, 1984), many studies have shown the relationship between socioeconomic position and cultural participation in "legitimate culture." As Bourdieu and Passeron (1990) explained in their book about the education system as a reproduction of the class habitus, socialisation in a particular cultural background is embodied by individuals and oriented by their praxis. Cultural factor, then, is considered as a dependent variable of socioeconomic status (SES).

But what happens if we consider cultural participation as an independent factor of a new socialisation in education? In opposition to the reproduction theory of Bourdieu and Passeron, DiMaggio (1982) proposed a new theory of cultural capital as a factor of mobility among the low-SES classes, converting it into educational success in a context with low cultural capital. Recent studies confirm the capacity of the mobilisation of cultural capital in education for low-SES children (Blaskó, 2003; Jæger \& Karlson, 2018). As pointed out by Jæger and Karlson (2018), unequal distribution of cultural capital shapes educational inequality at the macro-level. But culture can also be a factor of mobility at the micro-level in a context of low cultural capital. This means that a specific project in a vulnerable neighbourhood can produce a reverse process of familiarisation of cultural capital for children from families with low cultural backgrounds. In the case of young people, we also take as a reference the theory of Willis (1990), which explores how the everyday culture of young "normal" people is full of creativity and cultural significance in the era of modernisation. We have to consider the encounter of youth creativity and cultural education as potential ways to reshape inequality.

In the specific case of arts education, the transformative capacity of the arts is often considered one of its contributions to fight educational exclusion (Belfiore, 2002; López-Peláez et al., 2018; Murrey \& Crummett, 2018) toward producing a more equitable society. As Milbrandt (2010) pointed out, democratic societies can use arts not only to maintain social traditions but to create frameworks for social justice, identity, and freedom.

Non-formal education can be defined as "the voluntary, but intentional, planned, and permanently flexible educational process, which is characterized by the diversity of methods, areas, and contents in which it is applied" (Herrera Menchén, 2006, p. 13). Non-formal education is provided by public institutions or private organisations apart from the school (formal education). The terms "formal education," "non-formal education," and "informal education" have been extensively discussed in the last 20 years and are no longer considered mutually exclusive terms (Brown, 2013; Chisvert-Tarazona et al., 2019; Herrera Menchén, 2006). In many cases, these educational models can be interrelated and non-formal education is something in between. In this sense, non-formal training includes a deliberate, voluntary decision to participate in certain educational processes that take place outside the educational system. 
In Spain, there is an important tradition of imparting nonformal education in very diverse fields: environmental topics, social education, socio-cultural animation, education for leisure time, education for peace or equality, education in democratic values, lifelong learning, etc. (Herrera Menchén, 2006).

Non-formal education can have as great an emancipatory capacity, as literature on social resilience (Bandura, 1993; Rodhes \& Schechter, 2012; Zarobe \& Bungay, 2017), on the "pedagogy of the oppressed" (Freire, 1970) or participatory education (e.g., Castelloe, \& Watson, 1999) have shown. Non-formal education contributes to relaxing some of the procedures of formal education that act as barriers to certain students, particularly those coming from more disadvantaged backgrounds. In this sense, non-formal education might be a precious resource for the artistic education of young people growing up in vulnerable areas. In this regard, the value of non-formal education, very often promoted by civil society actors, is to make access to culture and arts possible in a vulnerable context. The capacity to develop participatory and inclusive methodologies based on promoting a sense of freedom and empowerment of adolescents and young people appears a remarkably influential aspect. This is considered one of the key factors to enhance the capacities of young individuals to develop themselves as creative and confident persons. In parallel, the involvement of the community in the educational process, in a less formal way than that used at school, reinforces the effect of empowerment on adolescents and young adults involved. The non-formal education methodology tends to foster creativity, horizontality, and openness, and this represents an opportunity to include the interests of pupils and their cultural background in a more flexible way into the learning process. We understand that this leads to social inclusion by involving young people from disadvantaged backgrounds in community activities and strengthening personal and collective self-esteem (Greene et al., 2013).

Moreover, non-formal education through the arts can help young people acquire resources and develop their cultural and artistic skills and interests, promoting creativity as an inclusive strategy and as a form of cultural expression (Glăveanu, 2011). This approach allows young people to develop their own resources and capacities to get involved and create cultural activities while acquiring artistic skills. This also implies that the cultural activities are conceived within social relations, in the community, and with a participatory perspective, because culture defines our relationship with the community and our role in it (Giroux, 2001). In addition to the teaching methodologies, cultural creation and cultural skills can be considered tools for social transformation, considering the capacity of cultural creation to build imaginaries in which young people feel represented. Hence, being creative and involved is key in ensuring young people are included in what we understand as cultural practices. Thus, non-formal education in the arts can repre- sent an extraordinary activity to enhance personal and collective empowerment.

This article aims to contribute to the literature on the potential of culture as a tool for emancipation and social inclusion. Specifically, through the analysis of a case study, we want to show how the combination of arts teaching and non-formal education offers an ideal environment for young people from vulnerable backgrounds to connect with their own potential and that of their community. Our research questions are oriented through the analysis of our case study to understand what values non-formal education spaces convey, how they work to engage diverse young people in their activities, the nature of the cultural learning that takes place in these spaces-as opposed to formal education, or even the family home-and, finally, how these processes of learning create an inclusive process in a specific deprived and culturally diverse area of Barcelona.

\section{Methods, Data, and Site Description}

\subsection{Methods and Data}

To explore how non-formal arts education can have an impact on youth empowerment and inclusion, an extreme case study strategy (Flyvbjerg, 2006) has been adopted. In this type of case study strategy, the selected case does not aim to represent a given universe but, precisely because of its uniqueness in some of the factors under study, it can demonstrate the potential of the phenomena studied under certain circumstances. The Center for Music and Performing Arts (CMPA) is taken as an extreme case study to investigate the role of non-formal music and arts education in social inclusion. As explained further, this centre has developed an unusual transversal, open, and flexible non-formal education working methodology specifically aimed at functioning across transversal aspects of the community and its individuals through the arts.

The case study combines non-participant observation of the different activities done by the organisation and semi-structured qualitative interviews with young people and educators. The fieldwork began in April 2019 and finished in October 2019. The first months were devoted to attending different meetings and activities by the organisation and gaining an understanding of the underlying dynamics. This marked an early stage in the process of selecting potential candidates (both educators and young people) for the interviews. Three researchers were involved in the fieldwork and we collected around 20 field diaries from the observations. The observation notes were used to understand the nature and the informal dynamics of the organisation. The field diaries consisted of a combination of descriptive notes of the activities, the relationships among young people and educators involved, and the subjective interpretation of the dynamics observed. The notes were compared and contrasted among the 
three researchers. Moreover, visual material (brochures, pictures, and videos) was also collected during the observation of many activities.

The interviews took place between June and October 2019. To select the young people for the interviews, we first chose potential candidates after an observation of the educational activities and then asked one of the educators for advice on the family background of our candidates (social class, life history, time involved in the project, current personal situation) to guarantee certain diversity among respondents. Concerning the interviewees' demographic profile, eight women and five men were interviewed. The age of the practitioners was between 43 and 60 years old and the young people were aged between 16 and 21. Two of the young interviewees were born in a foreign country and three were secondgeneration migrants. Some of the young people interviewed were living with a grandmother, aunts, or came from monoparental families. For eight of the 10 young people interviewed, their parents were either working in low-qualified jobs or unemployed. Thus, 13 interviews (10 with young people and three with practitioners) were conducted, transcribed, and anonymised.

For the analysis of the transcribed interviews, we used the NVivo 12 software. One single researcher was in charge of coding the entire project after having agreed on an initial proposal for the coding with the rest of the research team. Initially, the coding of the transcripts was based on the thematic topics of the interviews, but new topics emerged during the interviews that were also included. The purpose of coding the answers and comments of the interviewees was to make it easier to understand their meaning. The original first-level nodes were very scattered but also very illustrative, and they allowed for a very quick overview of the results. Once the coding was completed, some re-structuring and re-coding of the data was carried out. The quotes used here are the result of this codification process and were selected by their illustrative capacity of our main arguments.

\subsection{Site Description}

The CMPA is located in the Raval, one of the neighbourhoods with the greatest cultural and ethnic diversity in the city of Barcelona. The Raval is a historic neighbourhood in the centre of Barcelona that belongs to the Ciutat Vella District. It is located near the port and counted 48,688 inhabitants as of January $2021,56 \%$ of which was foreign, according to official statistics from the Barcelona City Council. After the Spanish, the most common nationalities are Pakistani and Filipino. It is one of the neighbourhoods in which people live in the worst conditions in the entire city, with education levels below the city average and many cases of substandard housing. It is the neighbourhood that receives proportionally more financial aid offered by the city's social services. To reverse this situation, there is a wide network of social and community organisations with social projects.
The Raval has a very rich artistic and cultural tradition. For over a century, it has welcomed working-class people from different migratory waves from other parts of Spain and around the world, creating spaces for artistic expression and cultural interaction. At the same time, it has suffered periods of institutional neglect and degradation. During the 1980s and 90s of the 20th century, the local administration promoted a policy of reformation and rehabilitation of houses, creation of open spaces (such as the Rambla del Raval), as well as the creation of facilities for the community. This project of urban regeneration was promoted, precisely, through major cultural projects (Jauhiainen, 1992) such as El Liceu, the Museum of Contemporary Culture of Barcelona (MACBA), the Center for Contemporary Culture (CCCB), or the Filmoteca de Catalunya, and aimed to strengthen the global brand of Barcelona by using the "authenticity" of the neighbourhood and its "cultural mestization" (Rius Ulldemolins, 2014). This has turned the Raval into a pole of cultural dynamism and tourist attraction coexistent with pockets of poverty and the social stigmatisation of part of its inhabitants.

The CMPA project started in 2005 on the initiative of a music foundation to fight social exclusion through the arts. The CMPA is defined as a socio-educational entity that works to promote a citizenship status for all people, fostering a culture of peace, respect for diversity, and social justice. The arts (basically music, theatre, dance, singing) are used as a means to achieve educational experiences. The CMPA's educational goals have a cultural focus, centred on cooperation and values. Although the majority of the teaching staff are of local origin, there are educators of other nationalities. They all have an artistic background but from varying paths: Some of them have earned higher degrees in music, theatre, choral, or artistic teaching, whereas others are self-taught. There is diversity in their ages and gender but they all share a very critical view of elitism in artistic training and a commitment to social education. They conceive of culture as a right for all to attain. The centre is financed with public and private funds and it has won several awards for its educational role through the arts, its culture of peace, and respect for diversity. The organisation plays an important role in the district's community network and also participates in educational activities outside their premises, linked to local intervention plans or the city's educational actions.

The main activities of the centre are aimed at children and young people (mainly from five to 20 years old), although they also work with parents or other older people, albeit less frequently. They organise learning activities like percussion, theatre, choral singing, as well as combo and orchestra workshops. Families pay a fee but, even if they cannot afford it, their children can still take part in the activities. Participants include people from the local neighbourhood and other parts of the city. The activities bring together a very diverse typology of families and young people. There are about 350 participants. Most 
people come by word-of-mouth, but there are also families or young people who are involved in the project on the recommendation of several social entities and other educational spaces of the district.

\section{Results of Analysis}

In this section, we present the empirical evidence produced by our research on how the CMPA is an example of youth empowerment through cultural participation. This should lead us to a more thorough understanding of the effects non-formal teaching of music and other arts have on inclusion and the acceptance of diversity. First, the reflections and experiences of the young participants and educators on how the arts and non-formal education, as a more relaxed and horizontal setting, facilitate empowerment processes are presented. Second, how these processes of empowerment contribute to social inclusion and enhance the transformative power of culture is examined.

\subsection{Empowering Disadvantaged Youth Through Non-Formal Arts Education}

Participant observation provided the research team with some evidence about the methodology of the centre and its environment. The school is located in a small building and families freely go and stay inside, waiting for their children while they are in the classroom. Classrooms are always open for the young people who wish to attend and they do not get into trouble if they go in after "lessons" have begun. The observation of teachers training the theatre group reveals a kind treatment of everyone, whatever the level of engagement and proficiency of the young people. They encourage each individual to improve their performance and make proposals, trying to adapt the text to their needs, interests, and levels of speech. They also respect the attitude of one young boy who seems insecure with the theatre play, is shy and stands away from the group all the time, but finally participates in his own way. During the observation period, students and educators were preparing a theatrical performance with dance, singing, and music of different styles and orchestra groups. The script of the play was centred on gender equality and in memory of the struggles of women in history. All the students and groups in the centre were to participate in the play, as well as some neighbourhood musical groups, including a rapper and a chorus of old women with disabilities. The play was performed in a neighbourhood theatre with 900 seats.

This is just an example of what can be observed in the CMPA. They use a methodology oriented to the inclusion of everyone: children, young adults, and families. Furthermore, we can observe an environment that is open to the needs and interests of the young participants, empowering them with competencies in music, dance, and theatre acting. Classroom dynamics are tailored to create group dynamics but respecting the rhythms, attitudes, and behaviour of all those involved. We observed some dynamics, as in a percussion class, which included young people with mental disabilities, mixing them with the other participants without barriers or precautions.

In this sense, we can deduce that artistic learning through different practices (playing an instrument, theatre, singing, dancing) is not an end in itself, but rather a mechanism for activating personal and collective experiences different from what these young people experience in their daily lives while making them learn other competencies and about values different from their own. Several practitioners recognise that music and the arts are disciplines that can be very powerful from an educational emancipatory perspective. The fact that music and performing arts can have an emotional impact on young people is highlighted by the educators and guides the learning process of the CMPA:

Music and the arts, in general, are extraordinary tools from an educational point of view, because they have an emotional impact, and the arts over time are so ephemeral, so we have to do it here and now, because of the nature of this language that allows you to mix diverse aspects at the same time, and the result is beautiful. And when you realise all this, you think: “What are we doing that means we don't use this anymore? (Sílvia, female, practitioner)

The process of teaching through artistic activities is an excuse to generate the climate and conditions for young people to learn to have more empathic and assertive relationships. A good environment is highlighted in the CMPA. For that, the student is treated as in a non-hierarchical relationship of equals:

Many people also develop close relationships with the teachers, since apart from music or guitar lessons, there is another bond and the trust that you feel. If something has happened to you, the atmosphere is good, and more so at this age when young people need spaces to speak and be listened. I think it's super important. (Veronica, female, young person)

I went [to the CMPA] to try modern singing. It was a discovery, really, because it's a place where you learn music, but music isn't essential, so music is what drives you there. You learn to experiment, not to be afraid, not to be afraid of making mistakes. Classes are experimental, [there's] no set pattern. If you're wrong, nothing happens, go back. It's not a school to read music, and if you don't know, for example, how to read music fluently this is not a barrier or obstacle for you to make music and this is what hooked me the most. (Cristina, female, young person)

The fieldwork, both from observation and interviews, reveals that CMPA practitioners are very aware of the 
environment in which their training activity takes place, as well as the profile of students and the need to prioritize empowering experiences, offering young people tools to grow personally and improve their environment. This involves, for example, learning to develop empathy towards others and have self-esteem, learning to work together and becoming aware of the context the individual inhabits. Some of these values that guide the process of artistic learning are expressed by one of the practitioners interviewed:

Interviewer: Could you explain to me what values you want to convey to the children and young people from your project?

Respondent: Trust. Self-esteem. Self-image. Humanism. Positive values. Respect. Freedom. Feeling comfortable. Being comfortable without being forced. (Hector, male, practitioner)

At the same time, non-formal arts education also offers an opportunity to work together for collective empowerment. In CMPA other pedagogical methods are used that focus on working cooperatively, as a group-in the words of CMPA, in a "choral way." The use of artistic language in a choral way means that individuals need to become actively involved and make individual contributions within the framework of a collective, cooperative process:

I learned to work more as a team, to coordinate more with my stage partners. And if at one point I have a problem, something bothers me, and I am not happy with something, I have to express myself and say it, which is something they let me do here and not in my house. (Madelyn, female, young person)

They are strongly encouraged to come here to experience art, just so that you can enjoy it, not to be the musician, the actor of....What happens next, that many have a lot of talent, this is secondary. Here the emphasis is on coexistence, living with a group of people who do things, who have concerns in a relaxed workspace, without [the] artistic pressure [you would feel in] a conservatory or a theatre school that wants to get people to work professionally. (Marta, female, practitioner)

\subsection{Empowerment for Social Transformation and Inclusion}

In the environment of the CPMA, a climate of acceptance is generated, with much attention given to personal and emotional needs. From this starting point, it is also possible to work on collective dynamics, acceptance of the other, and community building. When young participants are asked what lessons they learn in the organisation, the most common answers involve (a) the expe- rience of community and a family feeling, (b) learning to interact with diverse people and accepting cultural diversity, (c) learning to work in groups and collectively, (d) learning to listen and share, and (e) the friendships that are created:

Interviewer: And what have you learned so far?

Respondent: Well, I've learned to listen. So, I have learned....Just as you learn to open your mind, you learn to open your ears and eyes. And it's very nice because here, I have changed the way I communicate. (Xavi, male, young person)

And another example:

Interviewer: When you said that the CMPA is not just about teaching you how to sing, read a score, or play an instrument, what did you mean?

Respondent: So, for example, the chorus: Everyone can come. That is to say, there is no "you're not coming because you sing badly." We always try it, to help others, to be cooperative, to be...how do you say that? Thinking about others?

Interviewer: Empathy, maybe?

Respondent: Empathy, yes! Be empathetic with people, always help everyone. Go all together, right? (Cristina, female, young person)

If one word has been prevalent during the interviews we conducted with young people at the CMPA when they were asked to define their educational environment, that word is "diversity." Their understanding of diversity is that each individual is unique and individual differences must be recognised. The dimensions that were most mentioned are ethnicity, gender, sexual orientation, socioeconomic status, and religious or political beliefs. Moreover, several young people we interviewed expressed an open and positive outlook towards cultural diversity, which in many cases has to do with their experience within the non-formal context:

What I like most is social inclusion. It's the fact that, no matter where you come from, how much money you have, what talents you have, your capabilities....It's a place where we all have to accept each other, we have to help each other, and we have to learn. It is total diversity. Honestly, I really like this idea. (Lila, female, young person)

The interviews also show that this work for the empowerment of young people participating in the activities also contains a purpose that transcends the young people themselves, and that is taking into account its effect on the community. This is evident in the discussion of 
the concept of culture. A common conception among the practitioners of the CMPA is that culture is closely linked to the world around us. Culture and access to culture are seen as relevant elements in the society we live in and practitioners want to transmit this to the young people involved. Concerning the concept of cultural education, the organisation follows the intercultural and critical pedagogy of Freire (1970), in which, through educational practices, individuals and society can be transformed:

\section{Interviewer: What do you understand by cultural education?}

Respondent: What Freire says: That the academy is too important not to leave it in the hands of the people, and so for culture it is the same. Culture is the heritage of humanity, and generating it is the heritage of the community. Therefore, with educational action you generate culture. (Sílvia, female, practitioner)

\subsection{Limitations of the Project}

The project also has its limitations. On the one hand, one of the practitioners explained to us that many of the vulnerable children who arrive at the centre when they are in primary school through the neighbourhood social entities or by recommendation from their school teachers stop participating when they reach their teenage years. In other words, the success of the project is conditioned by a proportion of young people who drop out due to various reasons, such as lack of personal motivation, family mobility, or severe family situations that make it difficult for some youth to maintain their involvement. In addition, young people are asked to dedicate themselves and commit to the project quite intensively, which often means that the most motivated are those who continue participating in the project in their teen years.

On the other hand, another constraint, according to some of the young people interviewed, is that artistic education that wants to be accessible to all sometimes makes it difficult to achieve a high level of proficiency, learn more technical skills, and excel (the case of music is mentioned several times) in playing an instrument. This makes it hard to be accepted at the competitive level of high education music centres in the city-which follow rigorous admission procedures and follow the official arts curriculum. For those young people whose wish would be to continue studying music or improve their mastery of an instrument, they need to go to other sorts of artistic centres - to cope with this situation, the CMPA tries to get some scholarships for some of their more skilful students:

Well, [the CMPA] is super inclusive and everyone has access [to the classes]. The problem, sometimes, is the fact that everyone has access here.... When I first started, I learned a lot of things and I grew a lot but, of course, there were also people four years older than me learning the same [thing] after a few years....So, this means that people who have been coming here for ages haven't got past the first steps of learning. (Xavi, male, young person)

\section{Discussion}

In our research, we have observed how inclusive arts education can be to adolescents and young people coming from vulnerable environments. Our research question was whether cultural and artistic learning can overcome the barriers that are often common against children from deprived environments. We have shown how non-formal education, through flexible methodologies, can provide tools for inclusion. By strengthening empathy, being adapted to the student process of learning, and creating cooperative work and youth involvement, the CMPA achieves a collaborative and motivational learning environment and the empowerment of young participants.

There is currently a consensus that artistic learning and performance provides skills for empowering individuals, encouraging expressivity and emotions, on the one hand, and creating ways to cooperate and share with others on the other. Non-formal education is also relevant and may be complementary to those educational processes applied in traditional formal education. More relaxed and experiential, non-formal education spaces can provide rich learning processes for youths and fight against educational exclusion (Belfiore, 2002; López-Peláez et al., 2018; Murrey \& Crummett, 2018). The evidence we have gathered from this case study analysis also supports this. The young people interviewed and the practitioners themselves have highlighted the great number of lessons in terms of cultural practices, values, and skills they have learned thanks to their involvement in these projects.

The first research question focused on how these non-formal organisations work and what values they convey to encourage diverse young people to participate in their activities. It is clear that these activities are adapted to their target participants and contexts: They are multidisciplinary, participation is voluntary, they are carried out in diverse spaces, they use participatory practices, and provide a relaxed learning environment. On the other hand, we have to aknowledge teachers' attitudes towards what Allsup and Shieh (2012) named a "public pedagogy," oriented to the "moral imperative" to care about others. In the case we analysed, there is a clear ideology (or ethics) about the need to work for social justice, gender equality, and respect for diversity. Commitment to the community is crucial to the practitioners involved and the management of the centre demonstrates leadership that reflects this. Learning music, singing, engaging in the performing arts, as we have seen, not only has an artistic component but it also involves a set of values about education as an inclusive process.

But how is "cultural learning" transmitted in these spaces of non-formal education different from formal 
education? In non-formal education, the process is richer and more interdisciplinary than the memorising or routine learning experienced in formal education. Cultural learning, in the non-formal and informal contexts we observed, is experiential (Gross \& Rutland, 2017). Young people learn by doing and by feeling emotionally touched. This means that there is an expressive link with the educational organisation, rather than an instrumental one, breaking down the logic of reproduction (Bourdieu \& Passeron, 1990). Learning through emotional experiences has positive incentives among young people and fosters their empowerment. These are very particular experiences that do not always take place in formal education (Bisquerra Alzina, 2010). Both the practitioners and young people we interviewed highlighted these more emotional and active educational processes as something that attracted young people to a learning process through cultural activities and the sharing of values.

Because of this, non-formal arts education seems to contradict the determinations of cultural gaps and overcome the idea of Bourdieu's (1977) "habitus." Hodkinson and Sparkes (1997), through an analysis of career decisions, discovered that life histories have to be understood through interaction with significant others and with the culture in which the subject is living. We can consider that young people's experience in the CMPA constitutes a new horizon of action for their decisions about their careers and their lives. The transformative capacity of these cases of non-formal education in the arts must be understood as an interactional change between the centre and young people, that creates new expectations about what can be done.

Therefore, in addition to the centre's values, the centre itself is important as a mechanism through which young people acquire skills and attitudes for their future (e.g., developing empathy and a critical perspective of the environment they live in, exploring their creative side, committing oneself to a project, and self-awareness). The approach of practitioners towards young people, in a more egalitarian and relaxed relationship, appears to be an important element of the process in the case analysed. Many young people and practitioners said that the centre was like a second family to them-and this has particular merit when we take into account that some of the young people came from unstructured families (for instance, single parenthood with scarce economic resources) and very vulnerable living conditions.

However, the case of the CMPA also allows us to see the limitations of this cultural education in disadvantaged environments. The lack of continuity in their artistic education for many of the young participants is one of these limitations. The other challenge is the capacity of the project to have an impact on their environment. Obviously, the CMPA project does not change the structural inequalities in the neighbourhood. The question here is whether it would be possible to implement this sort of cultural education into the formal education system to assay a more inclusive and participatory form of education. Otherwise, we have to maintain the point of view postulated by Bourdieu about the education system as a "reproduction of inequalities." We have seen the possibilities of another type of education as a way to break the social and economic barriers. But it remains as an example of a small case as long as it does not result in more global change. Undoubtedly, however, non-formal education can provide methodologies and solutions that help to increase equal opportunities, empowering pupils.

\section{Conclusion and Recommendations}

As a conclusion of this case study, we can highlight several key aspects that enhance the capacity of non-formal education and civil society, in its globality, through the idea of producing transformation and empowerment among young people in vulnerable neighbourhoods: the promotion of emotional ties to the learning process; flexibility and adaptation to the needs of each individual, an empowering process which enables young participants to make decisions, creating an environment of trust and empathy; and assuring the inclusion of the social and cultural diversity outside the arts centre inside the classroom.

Additionally, the diversity of cultural activities, educational styles, and organisational structures is very positive because different young people are attracted to different aspects of culture and education. Fostering a diverse spectrum of participation possibilities can give more young people access to opportunities. This could be approached ideally by involving young people from different social groups in the conceptualisation and development of educational programmes.

Supporting young people is proving to be the key to their inclusion. This accompaniment is a tool for empowerment, to build their self-esteem and create the possibility of having new life horizons through art. In this sense, treatment and care mechanisms are critical for young people's subjectivity and for improving their self-esteem and expectations (Parcerisa \& Montes, 2017). The contribution of non-formal education as a space for innovation in educational processes that promote inclusion, diversity, and flexibility must be a condition.

Finally, we recommend that cultural and educational policies must be oriented to facilitate the increasing activity of the organisations devoted to non-formal education in the arts to be accessible to anyone. Unfortunately, public investment in cultural literacy education appears to be increasingly targeted towards larger institutions (typically associated with high culture) and projects that are considered to produce either observable returns or economically self-sustaining cultural practices (CHIEF, 2020). Small initiatives need public support because they can work better in disadvantaged neighbourhood contexts, taking advantage of the proximity and the day-to-day 
interaction with neighbours and the social environment. The third sector can also play a key role in the social inclusion agenda of cultural urban policies and youth access to culture.

\section{Acknowledgments}

The article is based on research conducted within the international project Cultural Heritage and Identities of Europe's Future (CHIEF), funded by the EU Horizon 2020 research and innovation programme (grant agreement no. 770464). The authors would like to thank the young people and practitioners interviewed, and the reviewers and the editors of Social Inclusion for their valuable comments and suggestions.

\section{Conflict of Interests}

The authors declare no conflict of interests.

\section{References}

Allsup, R. E., \& Shieh, E. (2012). Social justice and music education: The call for a public pedagogy. Music Educators Journal, 98(4), 47-51. https://doi.org/ $10.1177 / 0027432112442969$

Bandura, A. (1993). Perceived self-efficacy in cognitive development and functioning. Educational Psychologist, 28, 117-148. https://doi.org/10.1207/ s15326985ep2802_3

Belfiore, E. (2002). Art as a means of alleviating social exclusion: Does it really work? A critique of instrumental cultural policies and social impact studies in the UK. International Journal of Cultural Policy, 8(1), 91-106. https://doi.org/10.1080/ 102866302900324658

Berg, M., Coman, E., \& Schensul, J. (2009). Youth action research for prevention: A multi-level intervention designed to increase efficacy and empowerment among urban youth. American Journal of Community Psychology, 43, 345-359. https://doi.org/10.1007/ s10464-009-9231-2

Bisquerra Alzina, R. (Ed.). (2010). La educación emocional en la práctica [Emotional education in practice]. ICE-Horsori.

Blaskó, Z. (2003). Cultural reproduction or cultural mobility? Review of Sociology, 9(1), 5-26. https://doi.org/ 10.1556/revsoc.9.2003.1.1

Bourdieu, P. (1977). Outline of a theory of practice. Cambridge University Press.

Bourdieu, P. (1984). Distinction: A social critique of the judgement of taste. Harvard University Press.

Bourdieu, P., \& Passeron, J. C. (1990). Reproduction in education, society and culture. SAGE.

Brown, E. J. (2013). Models of transformative learning for social justice: Comparative case studies of non-formal development education in Britain and Spain. Compare: A Journal of Comparative and Inter- national Education, 45(1), 141-162. https://doi.org/ 10.1080/03057925.2013.841469

Cargo, M., Grams, G., Ottoson, J., Ward, P., \& Green, L. (2003). Empowerment as fostering positive youth development and citizenship. American Journal of Health Behaviour, 27, S66-S79.

Castelloe, P., \& Watson, T. (1999). Participatory education as a community practice method. Journal of Community Practice, 6, 71-89. https://doi.org/ 10.1300/J125v06n01_06

CHIEF. (2020). Democratising cultural learning through a shift from inclusion to infusion (Policy Brief 2). http://chiefprojecteu.com/wp-content/uploads/ CHIEF-Policy-Brief-2.pdf

Chisvert-Tarazona, M. J., Ros-Garrido, A., Abiétar-López, M., \& Carro, L. (2019). Context of validation of nonformal and informal learning in Spain: A comprehensive view. International Journal of Lifelong Education, 38(2), 198-213. https://doi.org/10.1080/02601370. 2019.1582563

Council of Europe. (2017). Cultural participation and inclusive societies. A thematic report based on the indicator framework on culture and democracy. https://rm.coe.int/cultural-participation-andinclusive-societies-a-thematic-reportbased/1680711283

DiMaggio, P. (1982). Cultural capital and school success. American Sociological Review, 47, 189-201.

Eurostat. (2019). Culture statistics: 2019 edition. https://ec.europa.eu/eurostat/documents/ 3217494/10177894/KS-01-19-712-EN-N.pdf/ 915f828b-daae-1cca-ba54-a87e90d6b68b

Flyvbjerg, B. (2006). Five misunderstandings about case study research. Qualitative Inquiry, 12(2), 219-245. https://doi.org/10.1177/1077800405284363

Forrest-Bank, S. S., Nicotera, N., Matera Bassett, D., \& Ferrarone, P. (2016). Effects of an expressive art intervention with urban youth in low-income neighborhoods. Child and Adolescent Social Work Journal, 33, 429-441. https://doi.org/10.1007/s10560016-0439-3

Freire, P. (2000). Pedagogy of the oppressed. Continuum. Giroux, H. (2001). Beyond the corporate university: Culture and pedagogy in the new millennium. Rowman \& Littlefield.

Glăveanu, V. P. (2011). Creativity as cultural participation. Journal for the Theory of Social Behaviour, 41(1), 48-67. https://doi.org/10.1111/j.1468-5914. 2010.00445.x

Greene, S., Burke, K., \& McKenna, M. (2013). Forms of voice: Exploring the empowerment of youth at the intersection of art and action. The Urban Review, 45, 311-334. https://doi.org/10.1007/s11256-0120228-z

Gross, Z., \& Rutland, S. D. (2017). Experiential learning in informal educational settings. International Review of Education, 63, 1-8. https://doi.org/ 10.1007/s11159-017-9625-6 
Herrera Menchén, M. d. M. (2006). La educación no formal en España [Non-formal education in Spain]. Revista de Estudios de Juventud, 74, 11-26.

Hodkinson, P., \& Sparkes, A. C. (1997). Careership: A sociological theory of career decision making. British Journal of Sociology of Education, 18(1), 29-44. https://doi.org/10.1080/0142569970180102

Jæger, M. M., \& Karlson, K. (2018). Cultural capital and educational inequality: A counterfactual analysis. Sociological Science, 5, 775-795.

Jauhiainen, J. S. (1992). Culture as a tool for urban regeneration: The case of upgrading the "barrio el Raval" of Barcelona, Spain. Built Environment, 18(2), 90-99.

López-Peláez, M. P., Martínez-Morales, M., MorenoMontoro, M. I., \& Tirado de la Chica, A. (2018). Historias de mi barrio: Contemporary art in a community at high risk of social exclusion. Educational Review, 70(5), 565-583. https://doi.org/10.1080/00131911. 2017.1353481

Milbrandt, M. K. (2010). Understanding the role of art in social movements and transformation. Journal of Art for Life, 1(1), 7-18.

Murrey, M., \& Crummett, A. (2018). Combating social exclusion through community arts. In A. Walker (Ed.), New dynamics of ageing (Vol. 1, pp. 129-146). Policy Press. https://doi.org/10.1332/policypress/ 9781447314721.003.0007

Parcerisa, L., \& Montes, A. (2017). El rol del tercer sector en la inclusión dels joves: Estudi de cas d'una entitat socioeducativa del barri del Raval (Barcelona) [The role of the third sector in the inclusion of young people: A case study of a socio-educational entity in the Raval district (Barcelona)]. Temps d'Educació, 53, 143-162. https://doi.org/10.1344/TE2017.53.10

Pineda-Herrero, P., Agud-Morell, I., Ciraso-Calí, A., \& Soler-Masó, P. (2018). In their own words: Elements of youth empowerment in Spain. Journal of Social Service Research, 44(5), 601-613. https://doi.org/ 10.1080/01488376.2018.1476290

Rius Ulldemolins, J. (2014). Culture and authenticity in urban regeneration processes: Place branding in central Barcelona. Urban Studies, 51(14), 3026-3045. https://doi.org/10.1177/0042098013515762

Rodhes, A. M., \& Schechter, R. (2012). Fostering resilience among youth in inner city community arts centers: The case of the artists collective. Education and Urban Society, 46(7), 826-848. https://doi.org/ $10.1177 / 0013124512469816$

UNESCO. (2012). Measuring cultural participation: 2009 framework for cultural statistics handbook no. 2. UNESCO Institute for Statistics.

Willekens, M., \& Lievens, J. (2014). Family (and) culture: The effect of cultural capital within the family on the cultural participation of adolescents. Poetics, 42, 98-113. https://doi.org/10.1016/j.poetic.2013. 11.003

Willis, P. (1990). Common culture: Symbolic work at play in the everyday cultures of the young. Open University Press.

Zarobe, L., \& Bungay, H. (2017). The role of arts activities in developing resilience and mental wellbeing in children and young people: A rapid review of the literature. Perspectives in Public Health, 137(6), 337-347 https://doi.org/10.1177/1757913917712283

\section{About the Authors}

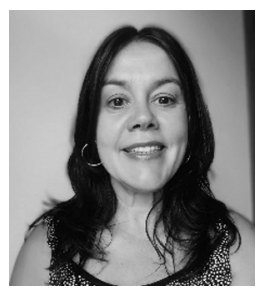

Mariona Ferrer-Fons is a postdoctoral researcher at the Political and Social Sciences Department of the Universitat Pompeu Fabra. She has been involved and led several national and international projects. Her research focuses on youth studies, participation, inequalities, and public health. She led the CHIEF project for Spain.

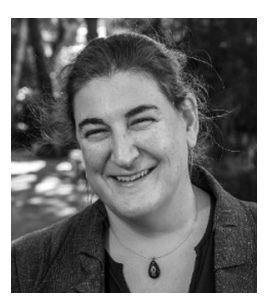

Marta Rovira-Martínez is a researcher, public policy consultant, and associate professor at the Autonomous University of Barcelona, where she earned her PhD in sociology. She was a researcher of the CHIEF project. Her research focuses on the fields of culture, language policies, identities, and immigration. She has also directed two documentaries.

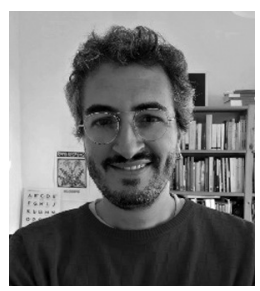

Roger Soler-i-Martí is a postdoctoral researcher at the Youth, Society and Communication Research Group (JOVIScom) of the Universitat Pompeu Fabra and a visiting research fellow at Aston University (United Kingdom). His research focuses on youth, political attitudes and participation, inequalities, social movements, and political ecology. He has participated in and led several national and international projects in these fields. 